\title{
Investigation of the structure of cement conglomerates
}

\author{
D. N. Shabanov, E. Trambitsky, E. Borovkova \\ Polotsk State University, Department of construction production, faculty of civil engineering, \\ Novopolotsk, The Republic of Belarus
}

\begin{abstract}
This article describes the structural studies of a cement conglomerate, its evolution from the moment of formation to the loss of operational properties. Physical and chemical phenomena and interactions of various elements of cement stone are considered. The study of its rheology includes creating a virtual model and monitoring the formation of the structure of cement pastes by acoustic emission (AE). The results of combined experimental studies to determine the residual life of cement stone samples using $\mathrm{AE}$ and tensometry methods are presented. The authors created a complex for monitoring the stress-strain state of artificial conglomerates, which includes both internal and acoustic sensors.
\end{abstract}

\section{Introduction}

Cement conglomerates actively form their properties during operation, and occurring changes have both positive and negative effects on their structure at different scale levels. When studying the formation of internal defects of agglomerates, it is important to pay attention to their structure. Actual studies show a significant impact of micro-destruction on the strength and deformation properties of concrete. It has been established that the process of micro-destructions begins when the stresses in concrete are much lower than its tensile strength and can decay or develop over time [1]. It is believed that the cause of the first micro cracks is the concentration of stresses near structural defects: pores, inclusions, dislocations. The study of physical processes causing the development of micro-destruction is of both scientific and practical interest.

According to modern concepts, micro cracks appear at low-stress levels of $0.3 \sigma_{\max }$ (the value of the parameter is determined for a specific cement sample based on the results of a press compression test). The destruction of concrete begins with the development of cracks in the contact zone (matrix - aggregate) with their subsequent exit into the matrix. Contact cracks develop under the impact of shear stresses, and cracks in the cement matrix develop under the action of tensile stresses [2]. All of these cases are caused by expansion or contraction of the intra-porous phase, which leads to deformations in the structure, then to stresses, which at a critical value form cracks in the structure [3]. From the standpoint of mechanics, the structure of any system is characterized by a set of properties that determine the ability of this system to resist destruction. This complex concept, applied to dispersed systems, must be differentiated by the following elements:

1) Structure of the substance in terms of chemical and mineralogical composition 
2) Geometric structure, which does not depend on the structure of the substance and is determined by a group of parameters characterizing the geometric structure, the relative position in the volume of the elements (particles and pores) that form the system

3) Structure of energy communication between individual elements of the system.

The combination of the listed elements determines the physical and mechanical properties of the material and forms the concept of the structure [4].

Considering the structure of cement stone, V.N. Jung called it micro-concrete, in which the resulting cement gel acts as a binder, and unhydrated clinker grains as a filler [5]. Structural models of a cement stone look like porous concrete. They contain cement grains with unhydrated cores and neoplasm shells that grow together in contacts.

Based on the above, the current issue is the study of the cement system structures, the formation of their initial defects, and the possibility of their detection at an early stage. Information about the behavior of materials at various scale levels is extremely important for evaluating the reliability, durability, and performance of the structural elements, as well as for creating new materials and technologies.

The main purpose of the work is to study the structure of cement conglomerates from the moment of contact of the components with water to the moment when the final structure loses its performance properties. When studying the initial stage of concrete structure formation, $\mathrm{AE}$ and computer modeling methods were used, which allowed to reliably predict the resource of cement conglomerates and identify production defects. In the study of the stress-strain state of concrete after reaching the design age, the methods of $\mathrm{AE}$ and tensometry were also used. According to the hypothesis, the combination of these methods allows to control areas of elastic deformations of natural and artificial conglomerates and determine the critical point with high confidence, thereby avoiding the accumulation of plastic deformations.

\section{Experimental part}

\subsection{Evolution and formation of the cement stone structure}

Computer modeling is used when it is necessary to take into account the internal material structure influence on the processes under consideration, when the substance is considered as a set of solid particles. Thus, using special software and modeling methods, it is possible to study the most effective approach to obtaining cement concrete of optimal structure and design and adjust various grain compositions of the concrete mineral part, modeling the internal structure of composite mixtures, and make a parametric assessment of the optimal degree of the compositions. The most reliable results are achieved using both simulation and experimental methods of research.

To simulate the cement conglomerate microstructure, Virtual Concrete and Cement Testing Laboratory (VCCTL) [6]was used. That software was developed by the National Institute of Standards and Technology (NIST), USA. The program simulates 3D microstructures of the cement systems and allows the prediction of the final properties of the final structure. The hydration of these microstructures can be modeled according to different hardening conditions (Figure 1), and the resulting hardened material can be analyzed for a number of properties, including linear elastic moduli, compressive strength, and relative diffusion coefficients. 3D - packaging of small and large aggregates in the mortar and concrete mixtures can also be created. 


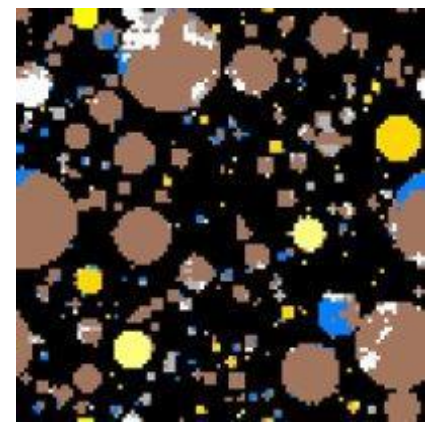

Ohr (without water)

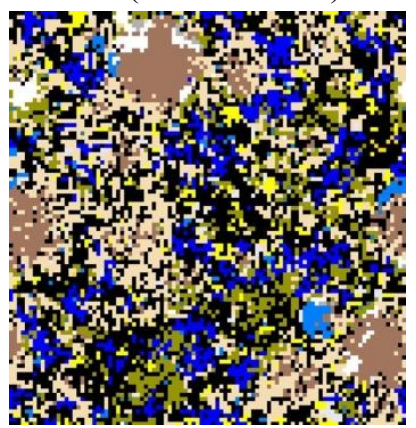

$72 \mathrm{hr}$

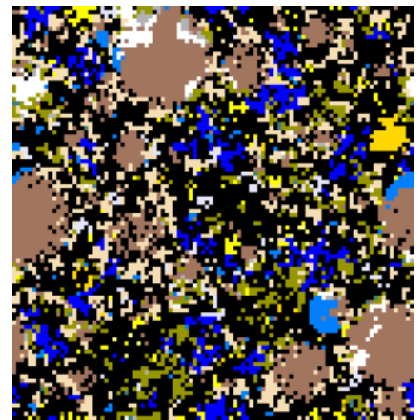

$24 \mathrm{hr}$

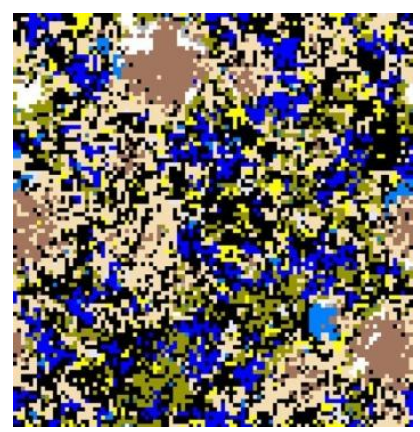

$96 \mathrm{hr}$

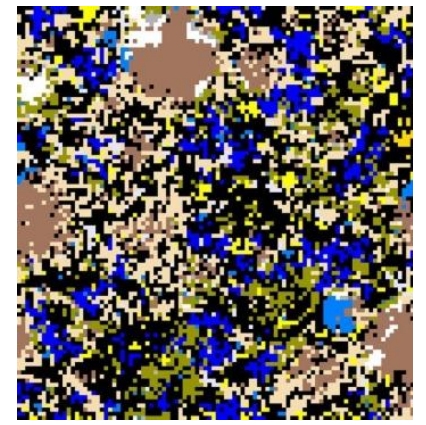

$48 \mathrm{hr}$

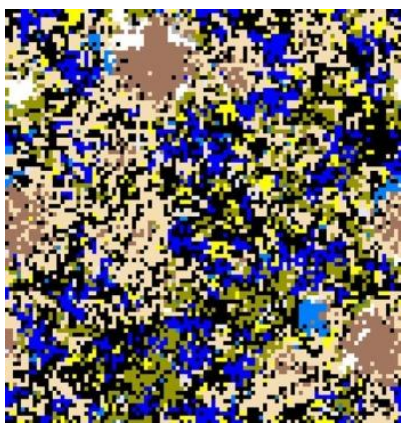

$120 \mathrm{hr}$

Fig. 1. Evolution of the cement stone structure.

The authors also created a virtual model of the cement composite structure in question. 3D-package of the final cement stone structure was created by converting 3 planes into one cube (Figure 2). The performed simulation made it possible to obtain different variants of the geometric shape of the aggregate and pores; it also indicates the ranges of their variation with the characteristic dimensions and orientation in the cement matrix space. 


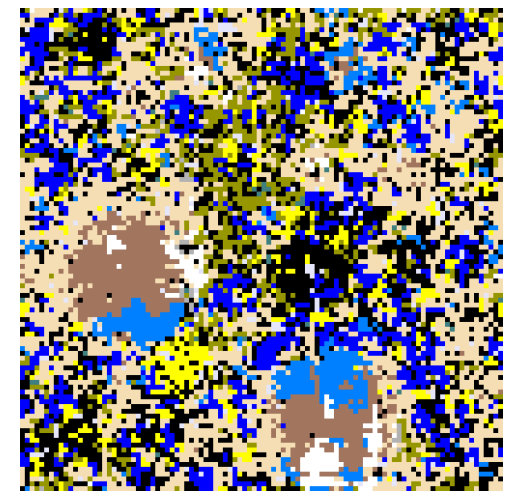

XZ-direction

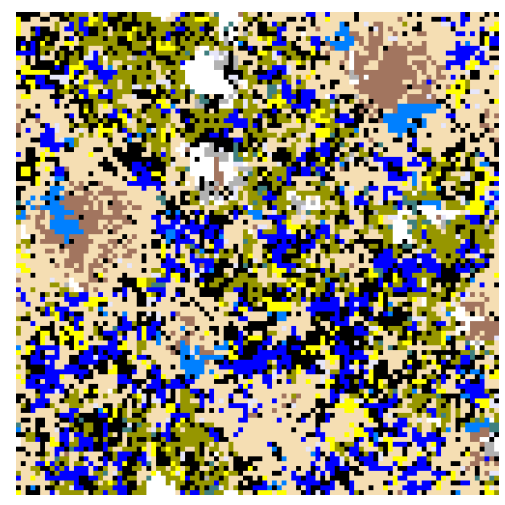

$\mathrm{XY}$-direction

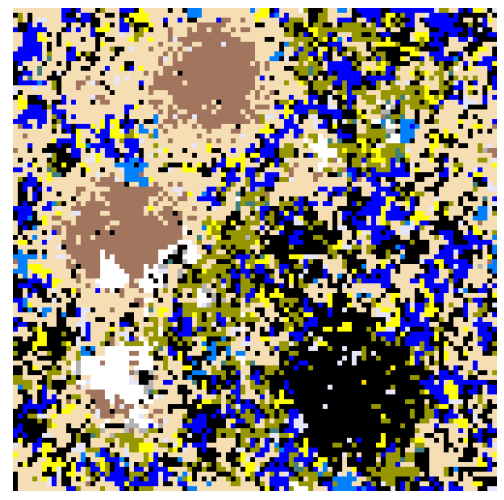

YZ-direction

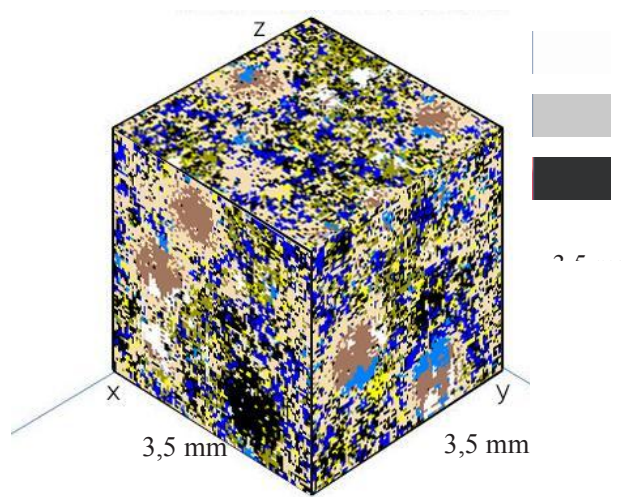

3D-package of the cement structure

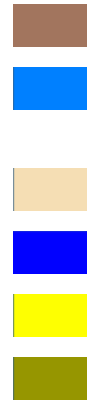

\section{Legend:}

$\mathrm{C}_{3} \mathrm{~S}$ (alit)

$\mathrm{C}_{2} \mathrm{~S}$

(belit)

C-S-H

$\mathrm{CH}$

Gypsum

Ettringit

Anhydrit

e

$\mathrm{C}_{4} \mathrm{AF}$

Other

Voids

Fig. 2. The virtual model of the cement stone (after 28 days).

This experiment is the basis for a computational experiment to obtain new data on the process of the gradual accumulation of damage in the structure of an artificial conglomerate under the static load.Once the final structure of the cement composite has been determined, a more complex model can be created in specialized software such as Solid Works, Ansys, etc., which will allow identifying weak links in the structure that will require closer monitoring in the future.

After computer modeling, i.e., virtual selection of the optimal concrete composition for certain conditions and its future testing, we made the samples of a cement paste in full-scale conditions. As mentioned earlier, monitoring of the early-stage material is very important, since this stage largely determines the final properties of the hardened concrete. Within the different monitoring techniques, $\mathrm{AE}$ has been recently increasingly used as it shows sensitivity in capturing the numerous elastic wave signals during the setting of the material and right from the moment of mixing [7].

Acoustic emission is the phenomenon of generating stress waves caused by a sudden rearrangement in the structure of material. Classical sources of $\mathrm{AE}$ are deformation processes associated with growing defects, such as cracks or foci of plastic deformation, during phase transformations associated with changes in the crystal lattice.

The structure of concrete is extremely complex, being in continuous dynamics from the moment the concrete components come into contact with water to the moment the concrete 
structure loses its performance properties. Since the properties of concrete and its behavior are determined by its structure, it is necessary to look for a change in its dynamics for each alteration detected in it, and conversely, for each observed change in dynamics, we should look for a transformation of the structure

First, we examined samples from a freshly prepared cement paste. Using a piezoelectric transducer and supplementary experimental equipment, carried out the acquisition and analysis of parameters of acoustic emission signals of a cement paste with the definition of structuring.A concrete mixture is obtained by mixing cement and aggregates (sand) with water. Water in the concrete mix at the moment of laying in the formwork is in the state of chemical (hydration and crystallization 4-5 \%), physical and chemical (adsorption 20-25\%), and mechanical connection (water capture in thin capillaries, pores 70-75\%) [8].

Acoustic emission signals propagating to the sample surface significantly change due to the dispersion of the sound velocity, transformation of wave types during diffraction, reflection, refraction, and attenuation (Figure 3). The laws of acoustic wave propagation in a cement conglomerate are very complex. It is characterized by the variability of the acoustic resistance of its components, so any changes in the structure, and as a result of energy and power characteristics, will entail changes in the signal at the output of the transducer.

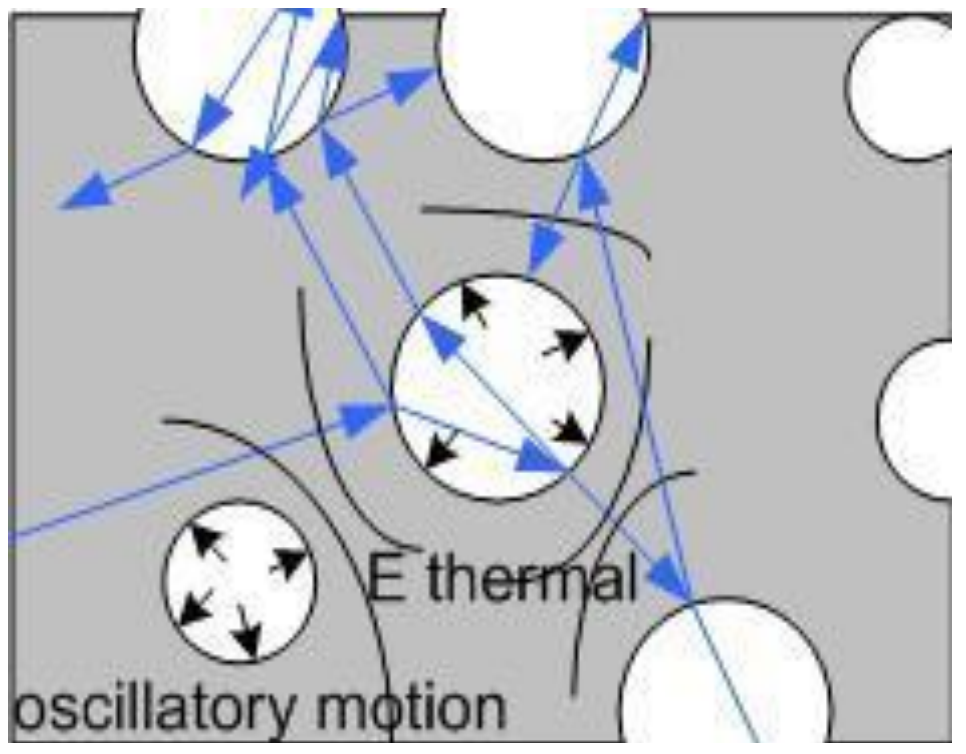

Fig. 3. Acoustic wave propagation inside a cement stone sample. 


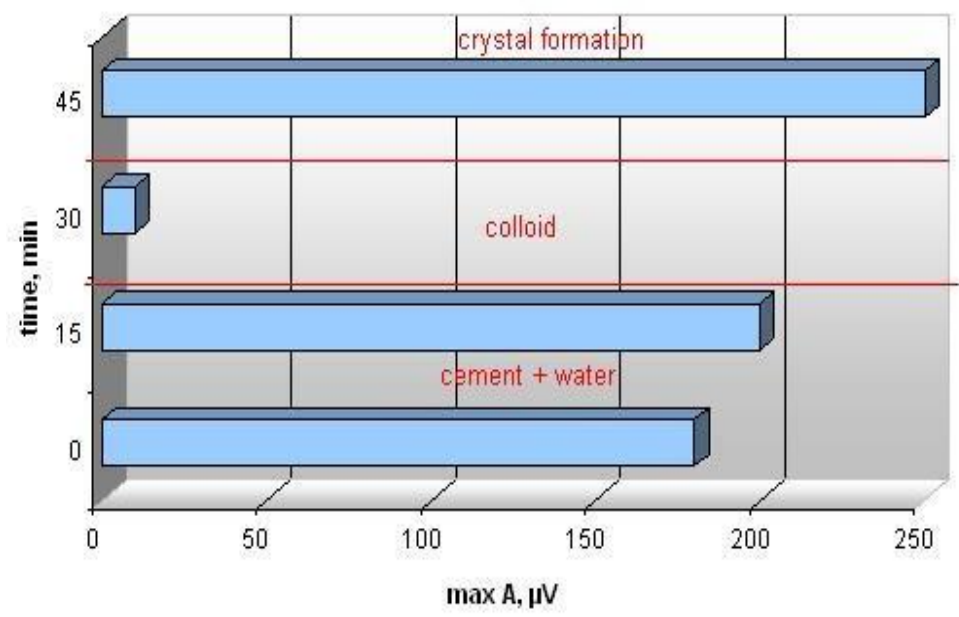

Fig. 4. Acoustic emission amplitude of cement solution due to the first 45 minutes.

Analyzing the readings, we identified structural changes with sharp abrupt differences in amplitude (Figure 4):

- Freshly prepared solution. This stage is accompanied by a constant bombardment of the surface by free water molecules due to their Brownian motion, the appearance of contacts between the newly formed and already growing particles of the new phase, as well as the migration of water and gas bubbles. The main source of $\mathrm{AE}$ at this level is mobility, the maximum signal amplitude $\operatorname{Umax}=200 \mu \mathrm{V}$.

- Occurrence of the colloids in a cement paste. The amount of free water decreases due to the reaction of hydration of ions by a certain number of water molecules, resulting in conditions for the formation of a double electric layer on the surface of the unreacted cement grain. Due to the hydration reaction, and as a result of an increase in heat generation, the energy of sound waves is dissipated, and therefore the intensity of acoustic waves decreases, i.e., the signal attenuation occurs, $\operatorname{Umax}=10 \mu \mathrm{V}$.

- Formation of the crystals. Due to the partially formed structure, the attenuation coefficient of sound waves is significantly lower than in the previous period, which is a consequence of an increase in the activity and amplitude of the recorded AE signals, Umax $=250 \mu \mathrm{V}$.

It is known that the shorter the duration of the crystallization period, the more intensive the process of concrete structure formation, i.e., the higher its final strength [9]. Thus, when studying the initial stage of structure formation of cement conglomerates, it becomes possible to influence the process of cement hydration, influence the beginning and end of setting, as well as to study the processes that occur in cement under the influence of various new additives in hardening concrete and cement stone. As a result, it allows to reliably predict the resource of concrete at the initial stage and identify production defects.

\subsection{Investigation of the stress-strain state of cement stone using tensometry and acoustic emission}

To determine the remaining resource, we studied cubic samples with a size of $100 \times 100 \times$ $100 \mathrm{~mm}$, made of cement stone with a water-cement ratio of 0.4 , after reaching the design age of 28 days after manufacture. This size was selected due to the convenience of placing several types of sensors at once, both outside and inside the tested samples. The samples 
were loaded using a press with a load step of $\sim 2.5 \mathrm{MPa}$. The data obtained during the tests are shown in Table 1.

Table 1. Compression test results for cement stone cubes

\begin{tabular}{|c|c|c|}
\hline Load number & Tension, $\mathrm{MPa}$ & Deformations, $\mathrm{mm}$ \\
\hline 0 & 0 & 0 \\
\hline 1 & 2.29 & 0.35 \\
\hline 2 & 5.23 & 0.47 \\
\hline 3 & 7.85 & 0.56 \\
\hline 4 & 10.23 & 0.68 \\
\hline 5 & 12.85 & 0.78 \\
\hline 6 & 15.43 & 0.89 \\
\hline 7 & 17.81 & 1.00 \\
\hline 8 & 20.27 & 1.09 \\
\hline 9 & 22.95 & 1.22 \\
\hline 10 & 24.93 & 1.32 \\
\hline 11 & 28.02 & 1.45 \\
\hline 12 & 30.37 & 1.56 \\
\hline 13 & 33.22 & 1.79 \\
\hline 14 & 34.90 & 1.89 \\
\hline- & \multicolumn{2}{|l}{} \\
\hline & \multicolumn{2}{|l}{} \\
\hline
\end{tabular}

The authors presented a measuring complex (Figure 5) used to determine the stressstrain state of cement systems with defects (cracks) in their structure at the micro- and macro-levels. This complex allows to present the mechanism of development of structural defects in cement systems as follows: using two types of sensors (embedded and acoustic emission), the formation and further development of micro defects in the structure of cement samples is monitored. In this case, the created system provides for the processing of several incoming signals at once, which implies its multichannel nature. With the use of both acoustic emission and tensometry methodology, it is determining the relationship between obtained signals and structural changes in the concrete or cement samples. Also, using several methods at the same time, we can achieve the necessary correlation of the final results.

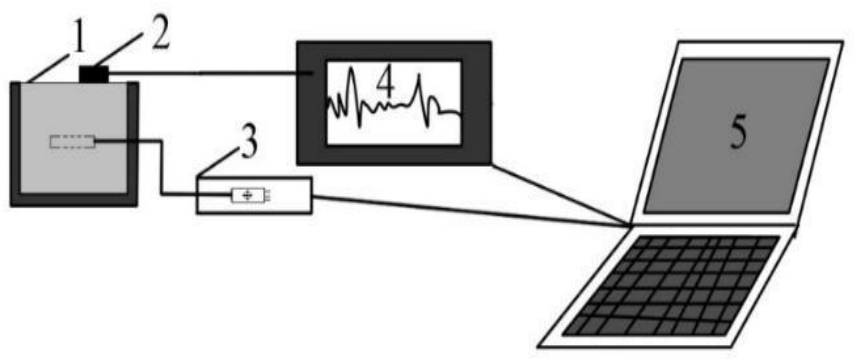

Fig. 5. Schematic diagram of the monitoring installation, 1 - cement stone with installed embedded sensor; 2 - piezoelectric sensor AE: 3 - microcontroller STM32;4 - oscilloscope; 5 - laptop.

This complex will be used to determine the transitional stage of cracking of concrete and reinforced concrete structures, according to the parameters of the sound wave (which in its turn characterizes the obstacles encountered) and an internal resistive strain gauge characterizing mechanical changes, not from the surface as usual but directly from the inside of the structure. The main feature of this system for monitoring the stress-strain state 
of cement composites is the simultaneous monitoring of mechanical stresses using tensometric sensors inside the sample (active method) and detecting acoustic emission phenomena with a piezoelectric transducer installed on the surface of the sample (passive method).

The tensometry method is characterized by using so-called "embedded sensors" or "internal strain gauges". The main concept of that sensor is the simple resistive strain gauge but in the casing of protective mastic, which allows it to organically integrate into the cement structure in question. This casing integrates well into the structure of the cement sample due to the fact that it has elasticity moduli and compressive strength comparable to cement stone, and a casing shape that has no sharp angles and therefore stress concentrations within the structure. That internal strain gauge is installed in a new structure at the molding stage directly at the most vulnerable places caused by the "red zones" based on the computer simulation results.

The main task of AE control is to identify indicators that reflect the formation and growth of cracks in a concrete structure, such as the place and time of formation, assessment of the size of the crack, and its evolution. Therefore, it is important to isolate and process the listed information from the general data set. First of all, AE streaming characteristics are used, such as activity (AAE), total count, number of pulses, and total count rate. Table 2 connects the flow characteristics of $\mathrm{AE}$ with the deformation mechanism during the entire test of the cement sample.

Table 2. Classification of the signal parameters depending on the integrity of the cement stone

\begin{tabular}{|c|c|c|}
\hline $\begin{array}{l}\text { Deformation and fracture } \\
\text { characteristics }\end{array}$ & $\begin{array}{c}\text { Characteristics of the AE } \\
\text { phenomena: }\end{array}$ & $\begin{array}{l}\text { Characteristics of the } \\
\text { tensometry system signals: }\end{array}$ \\
\hline $\begin{array}{c}\text { Compactionstage }(0 \sim(0.3-0.5)) \\
\text { of the breaking point: } \\
\text { - Shifts of the initial defects of the } \\
\text { material } \\
\text { - Breaking individual structural } \\
\text { bonds }\end{array}$ & $\begin{array}{l}\text { Isolated (rare) emissions with } \\
\text { weak amplitudes of high- } \\
\text { frequency signals }\end{array}$ & $\begin{array}{l}\text { Linear dependence of the } \\
\text { received signal from the } \\
\text { strain gauge on the applied } \\
\text { load }\end{array}$ \\
\hline $\begin{array}{c}\text { Micro cracks appearance stage } \\
(0.3 \sim 0.8) \text { of the breaking point: } \\
\text { - Occurrence of microcracks and } \\
\text { micro defects in local zones of } \\
\text { micro destruction } \\
\text { - Developing network of } \\
\text { microcracks is formed }\end{array}$ & $\begin{array}{l}\text { High frequency of pulses and } \\
\text { an increase in their amplitudes }\end{array}$ & $\begin{array}{l}\text { First voltage drops, the } \\
\text { voltage curve slides to a } \\
\text { plateau }\end{array}$ \\
\hline $\begin{array}{l}\text { Macro cracks occurrence stage } \\
(>0.8) \text { of the breaking point: } \\
\text { - Formation of main cracks } \\
\text { emerging on the surface } \\
\text { - Rapid development of } \\
\text { destruction }\end{array}$ & $\begin{array}{l}\text { Strong emission with large } \\
\text { amplitudes of low frequency }\end{array}$ & $\begin{array}{c}\text { Attenuation of a signal } \\
\text { followed by a decrease in } \\
\text { voltage in a tensometric } \\
\text { system }\end{array}$ \\
\hline $\begin{array}{c}\text { Active destructionstage }(>0.96) \\
\text { of breaking point: } \\
\text { - Complete destruction of the } \\
\text { material }\end{array}$ & $\begin{array}{l}\text { Short-term existence of the } \\
\text { emission with its rapid } \\
\text { increase before the } \\
\text { destruction of the sample }\end{array}$ & $\begin{array}{l}\text { Minimal voltage in the } \\
\text { tensometric system }\end{array}$ \\
\hline
\end{tabular}

Further recording and classification of the acoustic emission phenomena in the cement stone sample were carried out according to Table 2. The dependence of the maximum AE amplitude on the mechanical load is shown in Figure 6. Simultaneously with recording AE, the data obtained from the hydraulic press and embedded sensors were recorded using the 
PhyZ Module software. The data obtained during the experiment made it possible to plot the dependence of the change in the electric voltage of the tensometry system with increasing load (Figure 6).

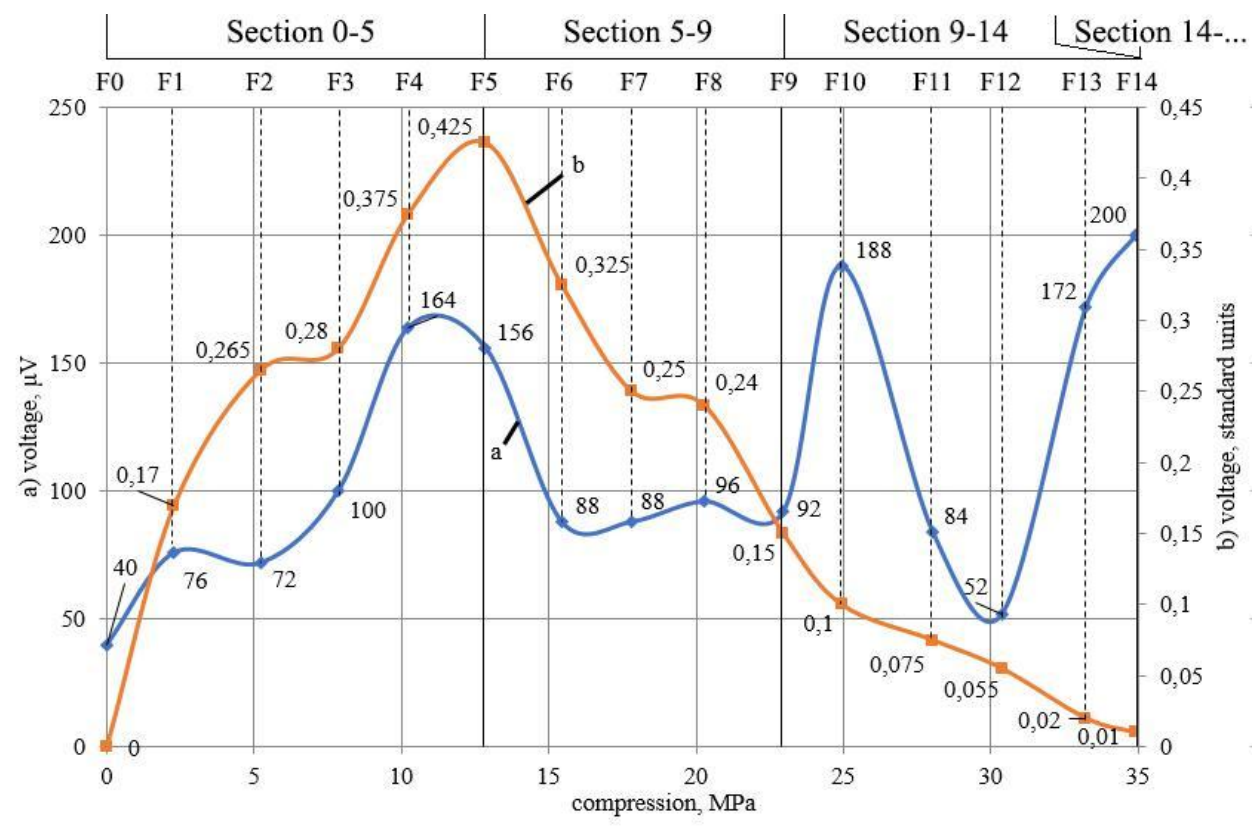

Fig. 6. Dependence of the sensor signals on mechanical load: a) AE amplitude; b) strain gauge system.

When loading the sample in stages upward, its total deformation consisted of the elastic and inelastic components, the ratio between which at different stages of loading was different. At the initial stage of loading, the weak bonds between individual structural elements are destroyed. In this case, mainly inelastic deformations will arise. This fracture is accompanied by significant acoustic emission activity, which can be seen from the Fourier plot (F0 - F14) shown in Figure 6 (a). At the stage (F0 - F5), the maximum deformation of the sample is $0.78 \mathrm{~mm}$. According to the data obtained from Table 2, that stage characterizes the structure compaction and the formation of micro cracks in the cement sample. When certain stress values are reached, a state of maximum compaction appears in the sample. The state of maximum compaction is taken to be point 5 , which corresponds to $12.85 \mathrm{MPa}\left(0.37 \sigma_{\max }\right)$. It can be concluded that in the state of maximum compaction, the elastic deformations are prevailing. According to the graph, we can also distinguish two additional zones, which correspond to inelastic and elastic deformations. Before reaching $12.85 \mathrm{MPa}$ (Section $0-5$ ), elastic deformations are prevailing, and then (Sections 5-9 and 9-14) the sample is going through the inelastic one.

With a further monotonic increase in the load, the ratio of less and more durable bonds between individual structural elements is constantly changing in favor of the latter. The stage of macro cracks formation is characterized with the reduction of the AAE and tensometry signals. It is a state of minimum acting and emerging defects, with a minimum of AAE arising under the influence of loading. This can be seen on the graph in Section 5 9. When the load exceeds a certain threshold value, new defects are formed and, as a consequence, the AAE grows, which can be seen in point 10 which corresponds to stress of $24.93 \mathrm{MPa}\left(0.71 \sigma_{\max }\right)$. 
Section 9-14 is the stage of active destruction of the cement sample. This stage is characterized by an "explosion" of the acoustic emission signal and a monotonic decrease in the strain-gauge signal. At this moment, acoustic emission signals allow determining the moment of the irreversible beginning of destruction of the structure (F9 - F14). At point 14, stress of 34.9 MPais observed, which indicates that the specimen has reached its ultimate strength. The final destruction of the cement stone test sample is shown in Figure 7.
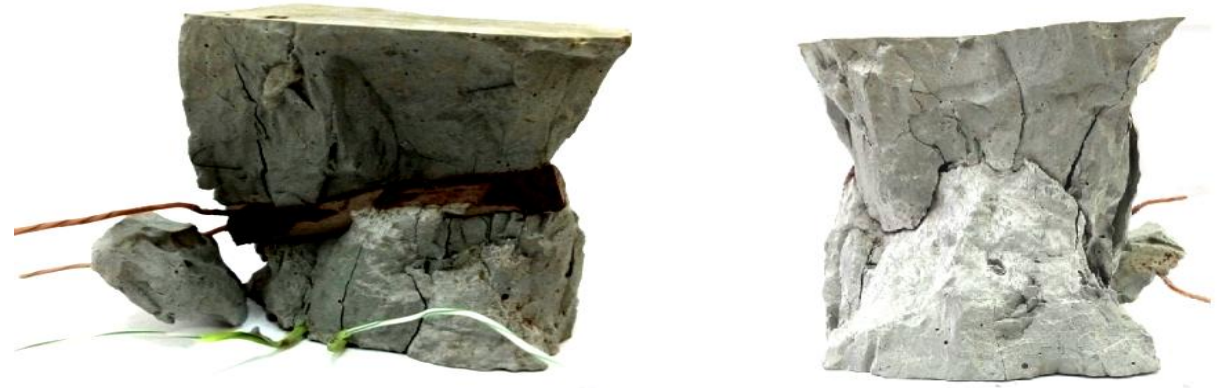

Fig. 7. Destroyed cement stone sample with an embedded sensor inside.

Finally, the proposed methodology for determining the stress-strain state of cement conglomerate structures involves an algorithm of the following actions:

1. Selection of the optimal cement composition based on its virtual simulation

2. Preparing a cement solution with installing an embedded sensor in it

3. Carrying out acoustic emission control of the cement paste structure formation to determine the ultimate strength of the future structure

4. Final monitoring of the structure using several types of sensors, such as monolithic structures using $\mathrm{AE}$ and tensometry methods, which translates into information on the occurrence and development of hazardous conditions in real-time, as well as determining the resource at any stage of operation.

\section{Conclusions}

Monitoring of the cement artificial conglomerates structure is a complex method requiring various tools. The authors used virtual modeling and acoustic emission methods at the initial stage to determine the relationship between acoustic signals and the processes of cement stone structure formation. At the next stage, the methods of acoustic emission and tensometry allowed to obtain the parameters of the operational and limiting stress-strain states of the cement structures under force actions.Based on these studies, it is possible to use combined methods of acoustic emission and strain measurement as a support for studying real concrete objects. The "embedded sensor" or "internal strain gauge" allows getting the tensometry signals providing information about the occurrence and development of dangerous conditions in real-time, as well as determine the resource at any stage of operation. As a structurally sensitive method, acoustic emission provides detection of plastic deformation, proper fracture, and phase transitions. These properties of both acoustic-emission and tensometry methods make it possible to form an adequate system of defect classification and criteria for evaluating the technical condition of the object, based on the real impact of the defect on the strength and performance of the object. 


\section{References}

1. A. Ahmedov, The effect of micro-destruction of concrete on the performance of building structures. Ph.D. dissertation abstract,Moscow.(2012).

2. D.Shabanov, A.Yagubkin, E.Borovkova, E. Trambitsky, Parameters of acoustic emission signals and their application in monitoring the state of the concrete structure. Bulletin of Polotsk State University. Series F. Construction. Applied sciences (8): 7478. (2019).

3. A. Podvalny, The mechanism of manifestation in the concrete of its deformations and stresses. Concrete and Reinforced concrete (4): 13-16.(2007).

4. A.F. Polak, V.V. Babkov, I. Sh. Fazulin, R.G. Habibulin, Description of the geometric structure of dispersed systems. Proceedings of NIIpromstroy17 (II):5-20,(1976).

5. V. Jung, Basics of binder technology. (Promstroyizdat. Moscow, 1951).

6. E. Garboczi, D. Bentz, K. Snyder, N. Martys, P. Stutzman, C. Ferraris, J. Bullard, Modeling and measuring the structure and properties of cement-based materials. An el. monograph: http://ciks.cbt.nist.gov/monograph(2010).

7. O.S.Dokunin, I.G.Koskov, V.P. Drutsk, S.A. Bernstein, Concrete and solvents for underground mine construction. Reference guide. (Nedra, Moscow, 1989).

8. D. D. Evin, Geert De Schutter, G.Dimitrios, Study on mechanical acoustic emission sources in fresh concrete. Arhives of civil and mechanical engineering (18): 742754,(2018).

9. V., Bardakov, A. Sagaidak, Predicting the strength of concrete during its hardening using the acoustic emission method.Flaw Detection (6): 40-43. (2017). 